\title{
New Organomineral Complex from Humic Substances Extracted from Poultry Wastes: Synthesis, Characterization and Controlled Release Study
}

\author{
Amanda M. P. Santos, ${ }^{a}$ Alexandre C. Bertoli, ${ }^{*}, a, b$ Ana Carolina C. P. Borges, ${ }^{a}$ \\ Raphael A. B. Gomes, ${ }^{a}$ Jerusa S. Garcia ${ }^{a}$ and Marcello G. Trevisan ${ }^{a}$ \\ ${ }^{a}$ Instituto de Química, Universidade Federal de Alfenas (UNIFAL-MG), \\ 37130-000 Alfenas-MG, Brazil \\ ${ }^{b}$ Departamento de Química, Universidade Federal de Minas Gerais (UFMG), \\ 31270-901 Belo Horizonte-MG, Brazil
}

\begin{abstract}
The present study reports the synthesis and characterization of complexes formed among humic (HA) and fulvic acids (FA) derived from poultry wastes and ions $\mathrm{Cu}^{2+}, \mathrm{Fe}^{2+}$ and $\mathrm{Zn}^{2+}$. The release of such metals in a buffer solution simulating the soil solution was also evaluated. After complexation, the Fourier transform infrared (FTIR) spectra presented alterations in the absorption bands related to changes in the humic structure, thus indicating the complexation with phenolic and carboxylic groups. Thermogravimetric analyses demonstrated that complexed metals decreased the thermal stability of humic substances. Analyses by atomic absorption spectroscopy (AAS) demonstrated that the release of metals is directly related to the origin of the sample, type of interaction of metal and humic structure and conditions of the medium in which the complex is inserted.
\end{abstract}

Keywords: humic substances, poultry wastes, organomineral complexes, spectroscopy, controlled release

\section{Introduction}

The sustainable agriculture looks for the use of preferentially organic fertilizers aiming not only the agricultural production but also the conservation of natural resources, thus increasing the fertility of soil and causing less environmental impacts. In this sense, organic matter plays a fundamental role since it is the main component of organic fertilizers obtained by physical and chemical natural or controlled processes from raw material of different origins enriched or not with mineral nutrients. ${ }^{1}$

Among several types of animal residues, chicken manure stands out since it is considered the main by-product of poultry farming and may be marketed as a natural fertilizer. The use of chicken manure as organic fertilizer is common, acting as source of nutrients for vegetable cultivation and corrector of biological, chemical and physical conditions of soil..$^{2,3}$ Humic substances (HSs) are among the main constituents of organic matter and represent important components for the soil, thus influencing the bioavailability of chemical elements and

*e-mail: bertolialexandre@yahoo.com.br being responsible by the transport and degradation of xenobiotics and other organic compounds. ${ }^{4}$

Some of the most commonly mentioned characteristics of HSs in the environment are its capacity to form complexes and precipitate cationic species, for example the metals, and also adsorb organic compounds. ${ }^{5}$ This is possible due to functional groups present in the chemical structure of HSs, like carboxylic, phenolic and ketone groups, which are responsible for the interactions with cationic species present where they are inserted..$^{5-7}$ The capacity of HSs to complex metallic species has been intensively studied, but considering that its structure is an intrinsic characteristic of each place in function of the origin, humidity and temperature, it is necessary to evaluate the complexation capacity of each sample separately. The strong interaction of HSs with metal species, such as copper, iron and zinc, culminates on the formation of a complex HSs-nutrients, thus influencing the availability and their transport for the plant, ${ }^{8}$ what makes HSs attractive for the agricultural sector.

Currently great part of fertilizers available in the market does not have organic matter in the composition, which makes more expensive for the agricultural production since the organic matter is incorporated by other source. Joining 
HSs (derived from organic matter) and mineral fertilizers in order to form a unique compound would be greatly useful for the sustainable agricultural development, since such compounds may release nutrients more slowly when compared to a traditional one. ${ }^{9}$

In this context, the present work aimed to present a post-treatment alternative to one of the by-products generated (humified organic matter) from poultry waste, in order to add value and a more sustainable final destination. Therefore, humic (HA) and fulvic acids (FA) were extracted from poultry wastes for synthesis with the metals $\mathrm{Cu}^{2+}, \mathrm{Zn}^{2+}$ and $\mathrm{Fe}^{2+}$. The characterizations were made by spectroscopic and thermal techniques, and the release of such metal in a buffer medium simulating the dilution of soil where plants are inserted was evaluated.

\section{Experimental}

\section{Methodology}

Samples of poultry wastes and extraction of humic fractions

In this study, samples of soil conditioner (SC) from poultry manure were used, which were conceded by the company Ovos Iana (situated in the municipality of Pouso Alto, MG, Brazil). Humic fractions of samples were extracted and purified using the methodology of extraction recommended by the International Humic Substances Society (IHSS). ${ }^{10}$

\section{Synthesis of organomineral complexes}

Synthesis were performed based on the studies of Litvin and Minaev ${ }^{11}$ and Litvin et al. ${ }^{12}$ Organomineral complexes were obtained by the following procedures: in a beaker, $0.08 \mathrm{~g}$ of HA and FA were weighed separately and $4 \mathrm{~mL}$ of $\mathrm{NaOH} 1 \mathrm{~mol} \mathrm{~L}^{-1}$ and $86 \mathrm{~mL}$ of distilled water were added on each beaker obtaining a final solution with $\mathrm{pH}$ 8. The solutions were heated until $35-40{ }^{\circ} \mathrm{C}$ in water bath during $30 \mathrm{~min}$ (overall six solutions were separated, three of HA and three of FA, one for each metal). The following reactants were used for the formation of complexes: $\mathrm{Fe}\left(\mathrm{NH}_{4}\right)_{2}\left(\mathrm{SO}_{4}\right)_{2} \cdot 6 \mathrm{H}_{2} \mathrm{O}, \mathrm{Cu}\left(\mathrm{NO}_{3}\right)_{2} \cdot 3 \mathrm{H}_{2} \mathrm{O}$ and $\mathrm{Zn}\left(\mathrm{NO}_{3}\right)_{2} \cdot 6 \mathrm{H}_{2} \mathrm{O}$. Two solutions of $10 \mathrm{~mL}$ were prepared with the concentration of $0.2 \mathrm{~mol} \mathrm{~L}^{-1}$ for each metal. Posteriorly these solutions were added to the previously prepared solutions of HA and FA. Beakers containing the final solutions were shaken at $180 \mathrm{rpm}$ during $30 \mathrm{~min}$ and then remained at rest from 24 to $48 \mathrm{~h}$, time enough for the solution decantation. Supernatants were properly identified and reserved in the refrigerator for posterior quantification. The precipitates (organomineral complexes) were dried in stove at $40{ }^{\circ} \mathrm{C}$ and then homogenized in porcelain pestle and mortar, identified and stored in polyethylene bottles.

\section{Characterizations}

\section{Elemental analysis}

The elemental analysis ( $\mathrm{CHN})$ was conducted in an elemental analyzer Leco Truspec, model CHN628, which detects carbon, hydrogen and nitrogen. Overall, $3 \mathrm{mg}$ of sample were used and analyses were conducted in triplicates.

\section{Fourier transform infrared spectroscopy (FTIR)}

In order to obtain the infrared spectra, the equipment iS50 FTIR (Thermo Scientic, USA) coupled with a Pike Gladi ATR Technologies was used. Analyses were conducted in the region from 4000 to $400 \mathrm{~cm}^{-1}$, with spectral resolution of $4 \mathrm{~cm}^{-1}$ obtained with 64 scans.

\section{Flame atomic absorption spectroscopy (F AAS)}

Supernatants derived from the organomineral complexes were analyzed by flame atomic absorption spectroscopy (FAAS) and then a difference mass/mass was determined between the concentration of iron, copper and zinc present in the supernatants and the concentration present in the precipitate of each complex. A spectrometer of Atomic Absorption Thermo Scientific model ICE 3000 Series was used and analyses were made in triplicates. The dilution factor was of 10 times for HA-Fe and FA-Fe and 20 times for $\mathrm{HA}-\mathrm{Cu}, \mathrm{FA}-\mathrm{Cu}$ and HA-Zn. Dilutions were not necessary for FA-Zn.

\section{Thermogravimetric analysis (TG)}

Thermogravimetric curves were obtained using the equipment of simultaneous analysis TG/DTA model TG/DTA 7300 of Exstar. From 3 to $5 \mathrm{mg}$ of each sample were weighed in alumina crucible and submitted to a controlled heating from the room temperature of approximately $27{ }^{\circ} \mathrm{C}$ to $1000{ }^{\circ} \mathrm{C}$ with a heating rate of $10{ }^{\circ} \mathrm{C} \mathrm{min}$ min $^{-1}$ under atmosphere of synthetic air with continuous flow of $100 \mathrm{~mL} \mathrm{~min}{ }^{-1}$.

\section{X-ray diffraction (XRD)}

X-ray powder diffractograms were obtained with $100 \mathrm{mg}$ of sample using the equipment Rigaku model Última IV, with $\mathrm{Cu} \mathrm{K} \alpha=1.54051 \AA$ between the $2 \theta$ interval $10-80^{\circ}$ with scanning speed of $4^{\circ} \mathrm{min}^{-1}$.

\section{Study of the metal release}

On each sample of complex $0.05 \mathrm{~g}$ were separated, which were placed in Erlenmeyers of $100 \mathrm{~mL}$ together 
with $10 \mathrm{~mL}$ of a buffer solution of potassium phosphate $0.1 \mathrm{~mol} \mathrm{~L}^{-1}$ at $\mathrm{pH}=6$. Experiments were conducted in triplicates under shaking in pre-determined times of 0,1 , $2,4,8,16,24$ and $48 \mathrm{~h}$ at room temperature. After shaking, the samples were centrifuged at $1000 \mathrm{rpm}$ to separate the supernatant for analysis. The quantification of metals after release study was conducted by F AAS.

\section{Results and Discussion}

\section{Elemental analysis}

The elemental composition of humic substances, as well as their properties, may vary according to the source of organic matter and place of formation. Even though determining the molecular formula of humic and fulvic acids represents a challenge, the elemental analysis is important since it provides an idea about the general composition of the molecule. The atomic ratios H/C, N/C and $\mathrm{O} / \mathrm{C}$ may be used to indicate the condensation degree, diagenetic transformations, as well as environmental conditions under which humic substances were formed..$^{13}$

Table 1 presents the results obtained by elemental analyses and the respective atomic ratios for humic and fulvic acids. The oxygen content was calculated by the difference.

It is observed that FA presented higher oxygen content and lower carbon content when compared to HA, which is in accordance with the literature. High contents of oxygen are characteristic of FA, which are constituted by smaller molecules and higher amounts of ionizable sites per mass unit in comparison with HA. It is also observed that FA presented lower ratios $\mathrm{H} / \mathrm{C}$ and $\mathrm{N} / \mathrm{C}$ and higher ratio $\mathrm{O} / \mathrm{C}$. The fraction with less aliphatic groups in the structure, i.e., more aromatic fraction, also presented more carboxylic and/or phenolic functions, which are responsible by forming complexes with hard acids. ${ }^{13}$

\section{FTIR - vibrational assignments}

According to the literature, ${ }^{14}$ the spectroscopy in the infrared region, despite presenting constraints regarding the structural characterization, is also valid for the identification of the functional groups present, as well as for studies of interactions between HSs and metals, thus revealing important characteristics about the complexation of diand trivalent cations. The vibrational spectra obtained for $\mathrm{HA}$ and FA, as well as for their respective complexes are presented in Figures 1, 2 and 3.

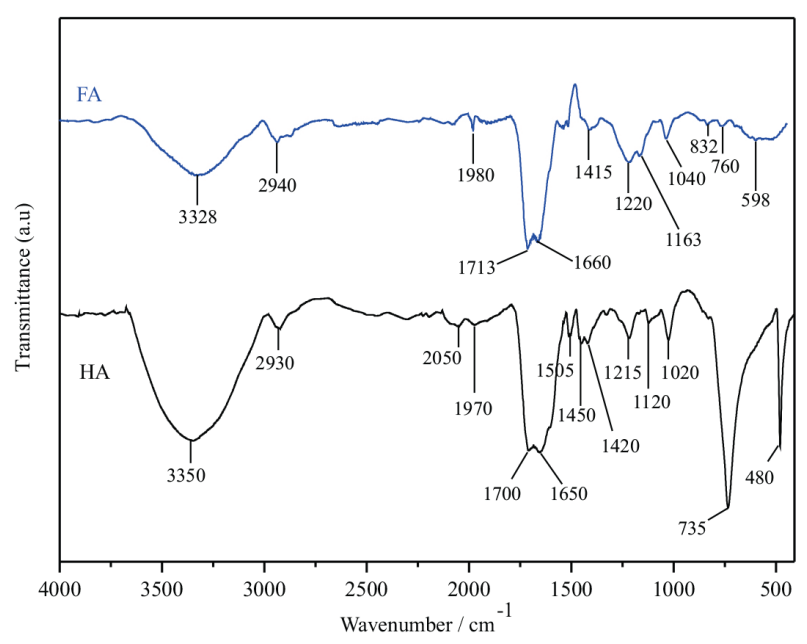

Figure 1. FTIR spectra of humic acid (HA) and fulvic acid (FA).

\section{Vibrations characteristic of $\mathrm{OH}$}

Absorption bands observed at the wavelengths of 3328 and $3350 \mathrm{~cm}^{-1}$ for FA and HA, respectively, may be attributed to the vibrations of $\mathrm{OH}, \mathrm{NH}$ and $\mathrm{CH}$ stretch, since they occur in the region from 3700 to $3200 \mathrm{~cm}^{-1}$ approximately. ${ }^{13}$ The absorption bands derived from $\mathrm{OH}$ generally came from the compounds that have water, carboxylic acids, alcohol and phenol present in the structure. Absorptions from $\mathrm{OH}$ stretch vibrations present in carboxylic acids are very peculiar, presenting a wide and intense absorption band at $3300 \mathrm{~cm}^{-1}$, that may be observed in the spectra. ${ }^{14}$

\section{Vibrations characteristic of $\mathrm{CH}$}

Absorption bands observed at the wavelengths of 2940 and $2930 \mathrm{~cm}^{-1}$ for FA and HA, respectively, may be attributed to the vibrations of aliphatic $\mathrm{CH}$ stretches, since they occur in the region from 3000 to $2800 \mathrm{~cm}^{-1}$ aproximately. ${ }^{13,14} \mathrm{~A}$ subtle difference of absorption is observed among the aliphatic $\mathrm{CH}$ stretches, since both absorption bands are located in a very similar range of the infrared spectra, thus hampering the accurate

Table 1. Elemental composition (C, H, N and $\mathrm{O})$ and atomic ratios (H/C, N/C and $\mathrm{O} / \mathrm{C})$ of humic and fulvic acids isolated from poultry manure

\begin{tabular}{lcccccccc}
\hline \multirow{2}{*}{ Sample } & \multicolumn{4}{c}{ Element / \% } & & \multicolumn{3}{c}{ Atomic ratio } \\
\cline { 2 - 5 } \cline { 3 - 7 } & $\mathrm{C}$ & $\mathrm{H}$ & $\mathrm{N}$ & $\mathrm{O}$ & $\mathrm{H} / \mathrm{C}$ & $\mathrm{N} / \mathrm{C}$ & $\mathrm{O} / \mathrm{C}$ \\
\hline Humic acid & 41.23 & 5.76 & 7.30 & 45.71 & & 1.68 & 0.14 & 0.83 \\
Fulvic acid & 33.68 & 4.37 & 5.02 & 56.93 & 1.56 & 0.12 & 1.27 \\
\hline
\end{tabular}



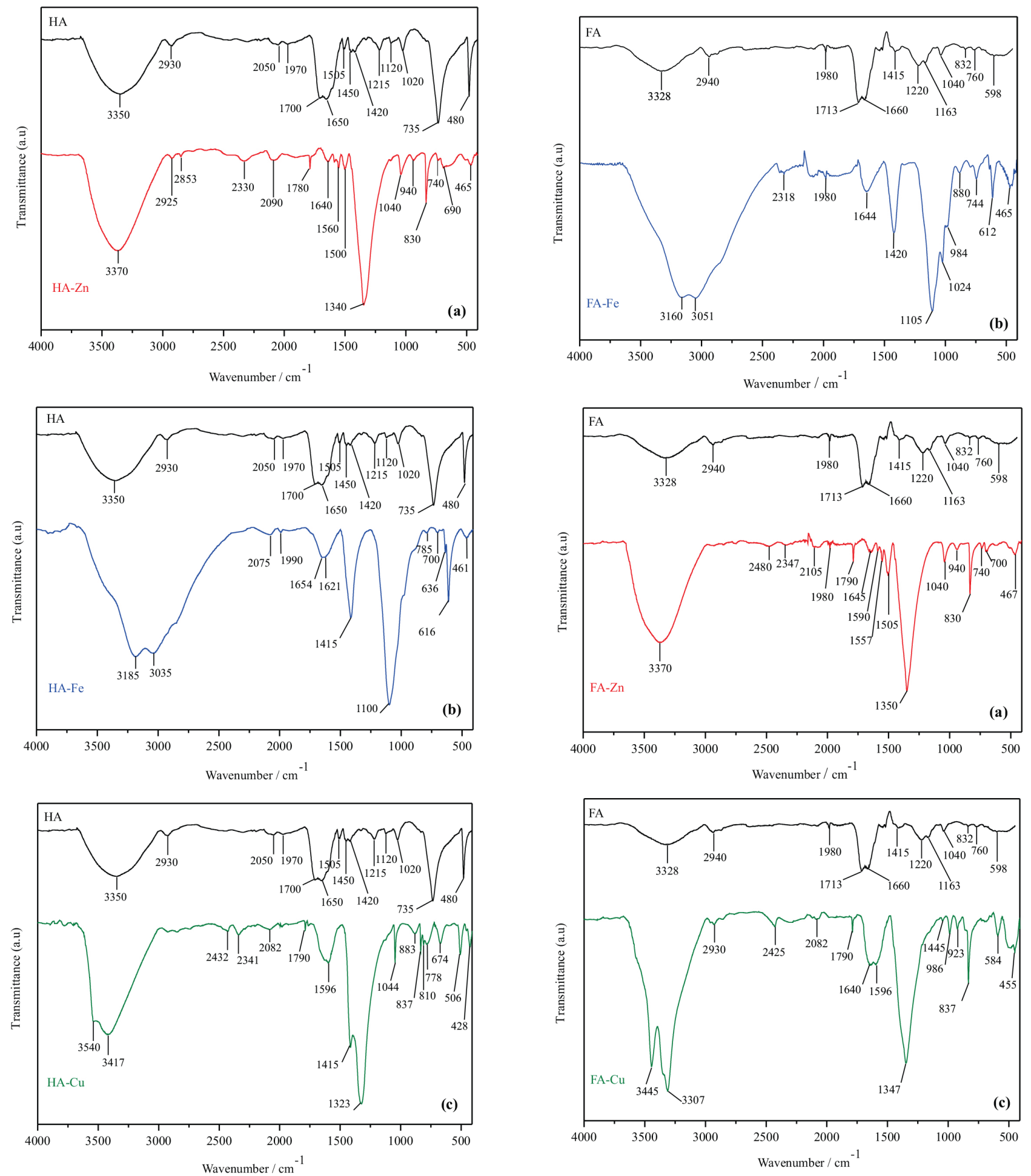

Figure 2. FTIR spectra: (a) spectra of humic acid (HA) and HA complexed with zinc (HA-Zn); (b) spectra of HA and HA complexed with iron (HA-Fe); (c) spectra of HA and HA complexed with copper (HA-Cu).

identification of the functional group. It means that the absorption bands present in the FA and HA spectra may be related to the asymmetric stretch of both $\mathrm{CH}_{3}$ and the aliphatic $\mathrm{CH}_{2} \cdot{ }^{15}$

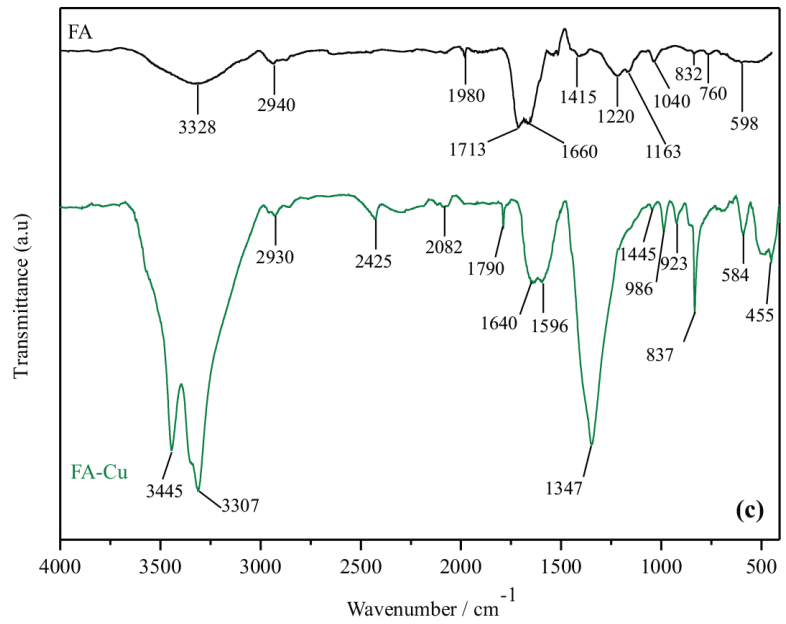

Figure 3. FTIR spectra: (a) spectra of fulvic acid (FA) and FA complexed with zinc (FA-Zn); (b) spectra of FA and FA complexed with iron (FA-Fe); (c) spectra of FA and FA complexed with copper (FA-Cu).

\section{Vibrations characteristic of $\mathrm{C}=\mathrm{O}$}

Absorption bands observed at wavelengths of 1713 and $1700 \mathrm{~cm}^{-1}$ for FA and HA, respectively, may be attributed to the vibrations of $\mathrm{C}=\mathrm{O}$ stretches from ketones and 
carboxylic acids. Carbonyl compounds absorb strongly in the region from 1870 to $1540 \mathrm{~cm}^{-1}$ of the infrared spectra, thus presenting an intense absorption band caused by stretch vibrations. The absorption ranges characteristics of carbonyl groups are influenced by effects caused by the chemical environment where they are inserted. Shifting an alkyl group by another one that have an inductive effect over the bond decreases its length, thus increasing the strength constant and consequently the displacement of absorption for a frequency of higher wave number. On the other hand, shifting by a group that promote the delocalization of electrons $\pi$, resonance or conjugation increases the bond length, thus decreasing the character of the bond $\mathrm{C}=\mathrm{O}$ and consequently displacing the absorption for a frequency of lower wave number. ${ }^{15,16}$

\section{Vibrations characteristic of $\mathrm{C}-\mathrm{O}$}

Absorption bands observed at the wavelengths of 1220 and $1215 \mathrm{~cm}^{-1}$ for FA and $\mathrm{HA}$, respectively, may be attributed to the vibrations of $\mathrm{C}-\mathrm{O}$ stretches of alcohols, phenols and ethers. Vibrational stretches of alcohol and phenol present a strong absorption band from 1260 to $1000 \mathrm{~cm}^{-1}$. Vibrations of $\mathrm{C}-\mathrm{O}$ stretches couple with the adjacent $\mathrm{C}-\mathrm{C}$ vibration, consequently in primary alcohol the stretch vibration may be much more effective when compared to alcohols with insaturations. ${ }^{13-17}$

\section{Absorption bands from 900 to $700 \mathrm{~cm}^{-1}$}

In this region, absorptions observed in the infrared spectrum are typical of $\mathrm{CH}$ angular deformations present in aromatic groups in and out of the plan. This absorption range may be attributed to the angular deformation of $\mathrm{CH}$ out of the plan caused by groups $\mathrm{R}_{2} \mathrm{C}=\mathrm{CHR}$ and angular deformation of two adjacent $\mathrm{H}$ of para-substituted and tetrasubstituted rings deriving from aromatic groups. The region of $760 \mathrm{~cm}^{-1}$ may be attributed to the angular deformation of five adjacent $\mathrm{H}$ of monosubstituted rings deriving from aromatic groups, angular deformation of four adjacent $\mathrm{H}$ from ortho-substituted rings of aromatic groups and angular deformations of ethyl groups. Some additional attributions are the angular deformation of propyl groups and $\mathrm{CH}$ out of the plan deriving from $-\mathrm{CH}=\mathrm{CH}-$ groups. $^{13-18}$

\section{Main vibrational assignments of complexes}

Spectra of complexes with HSs presented similar behavior with the displacement of the absorption band in the range of $1700 \mathrm{~cm}^{-1}$, related to the $\mathrm{C}=\mathrm{O}$ stretch of the carboxylic acid, 1650 to $1550 \mathrm{~cm}^{-1}$, related to the conversion of the band of absorption of $\mathrm{COOH}$ in $\mathrm{COO}^{-}$, and also the displacement in the range of $1200 \mathrm{~cm}^{-1}$, related to the $\mathrm{C}-\mathrm{O}$ stretch of alcohols, phenols and ethers. The formation of doublets for the spectra of complexes of iron and copper with HSs was also observed from the region 3540 to $3035 \mathrm{~cm}^{-1}$, a region characteristic of $\mathrm{OH}$ stretches. This may indicate that $\mathrm{OH}$ stretches of groups derived from alcohol or phenol and $\mathrm{OH}$ stretches of carboxylic groups participate together with the complexation with iron and copper ions. ${ }^{13-19}$

\section{X-ray diffraction $(\mathrm{XRD})$}

In general, the diffraction pattern of HA and FA present wide bands between $3.5 \AA$ (attributed to the more condensed carbon structure, i.e., aromatic structures) and $4.3 \AA$ (attributed to the structure of aliphatic carbons). ${ }^{20-23} \mathrm{X}$-ray diffractograms of HA and FA, as well as their respective complexes, are presented in Figures 4, 5 and 6.
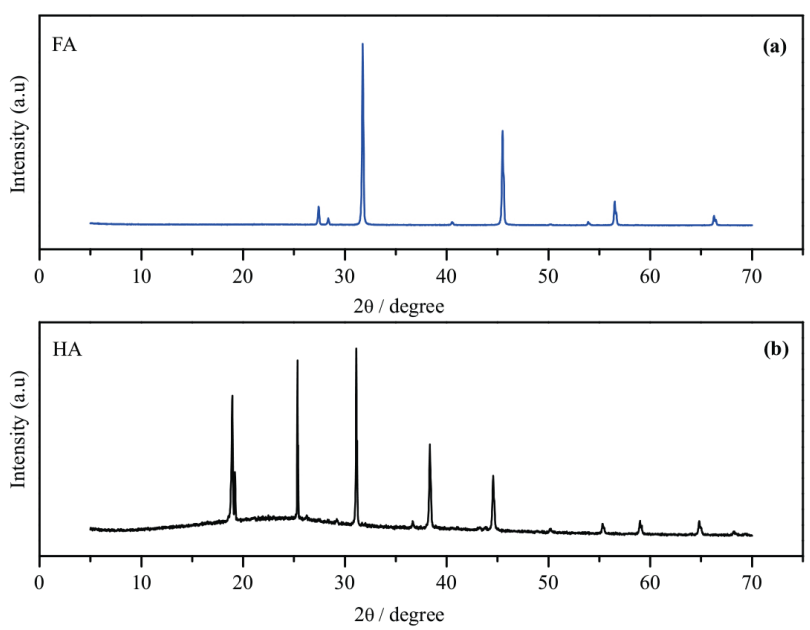

Figure 4. X-ray diffraction: diffractogram of (a) fulvic acid; (b) humic acid.

The diffractograms present several fine and well defined peaks characteristic of crystalline structures. One possible cause for this fact is that during the extraction process residues of the inorganic part deriving from humin may have remained in these fractions. According to what was mentioned in Methodology section, samples came from poultry wastes and chicken consume a great amount of sand when feeding to help their digestion. Since the sand is basically composed of $\mathrm{SiO}_{2}$, the fine peaks found in the $\mathrm{X}$-ray diffractogram may be related to the referred oxide..$^{24,25}$ However, since it is a macromolecule that may vary the composition and that still does not have a completely defined crystalline structure, the literature ${ }^{26}$ reports studies involving the aromaticity based on the percentage occupied by the bands $\gamma$ and $\mathrm{G}$ for the interpretation of X-ray diffractogram. The band $\gamma$ is attributed to the aliphatic 

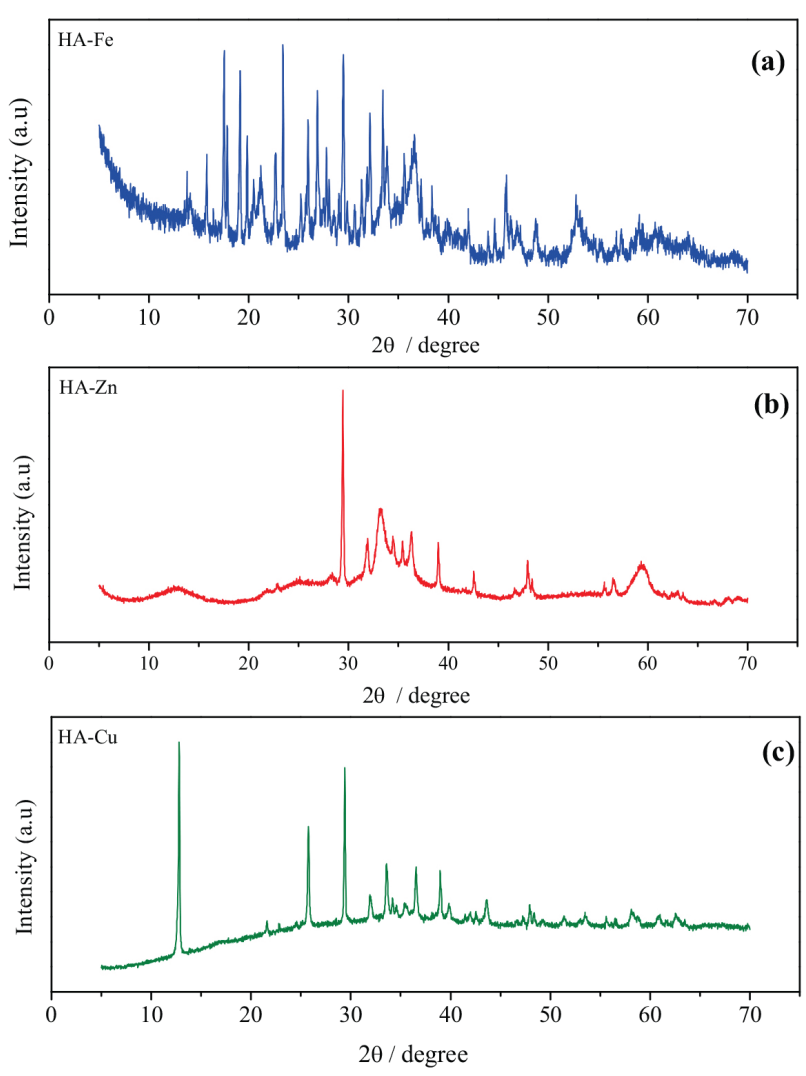

Figure 5. X-ray diffraction: diffractogram of complex of humic acid (a) with iron (HA-Fe); (b) with zinc (HA-Zn); (c) with copper (HA-Cu).
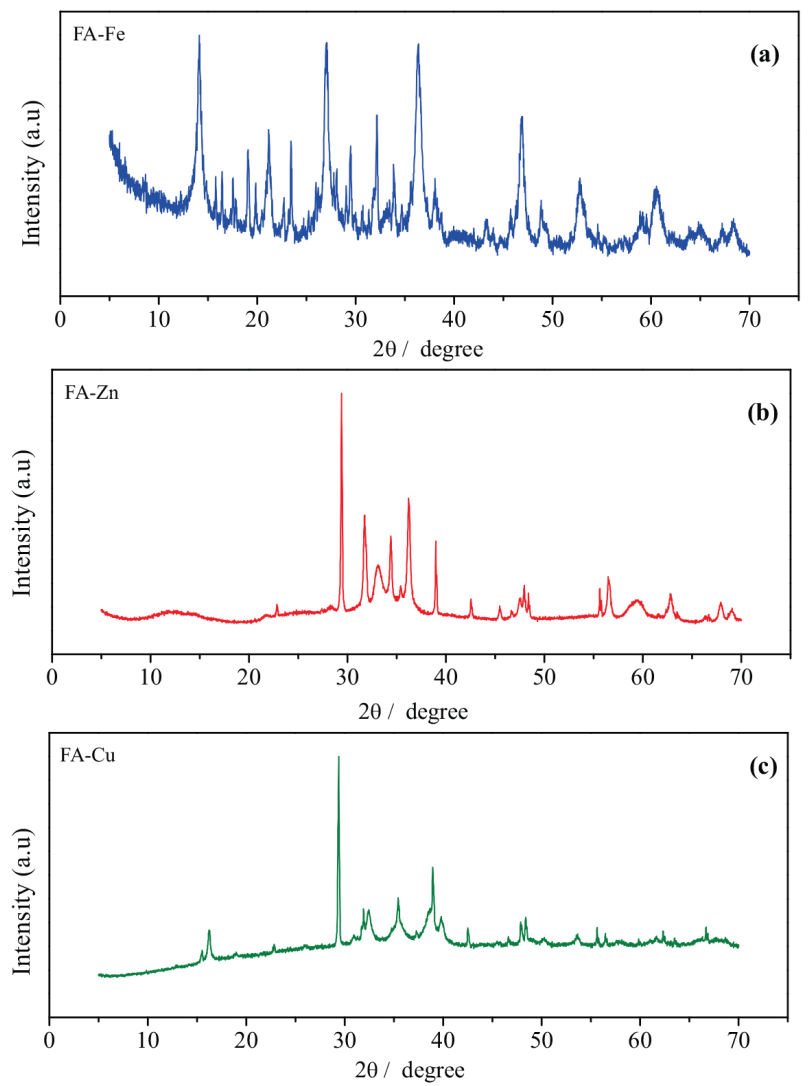

Figure 6. X-ray diffraction: diffractogram of complex of fulvic acid (a) with iron (FA-Fe); (b) with zinc (FA-Zn); (c) with copper (FA-Cu). groups of lateral chains, while the band $\mathrm{G}$ is attributed to the aromatic groups with ordering similar to those of the graphite plan (002). ${ }^{22}$ This study was successfully employed by some authors ${ }^{13,20,23,26}$ that reinforced the results of such technique.

Aromatic $(\%)=\frac{\text { Area of the peak BG } \times 100}{\text { Area of the peak BG }+ \text { Area of the peak B } \gamma}$

Aliphatic $(\%)=\frac{\text { Area of the peak } B \gamma \times 100}{\text { Area of the peak BG }+ \text { Area of the peak B } \gamma}$

where $\mathrm{BG}=$ band $\mathrm{G}$ (corresponds to the angle $2 \theta$ of $25.5^{\circ}$, or $0.35 \mathrm{~nm}$ in the X-ray diffractogram); $\mathrm{B} \gamma=$ band $\gamma$ (corresponds to the angle $2 \theta$ of $20.5^{\circ}$, or $0.43 \mathrm{~nm}$ in the X-ray diffractogram); Area of the peak $\mathrm{BG}=$ area corresponding to the peak of band G; Area of the peak $\mathrm{B} \gamma=$ area corresponding to the peak of band $\gamma$.

The calculation of the ratio of aromatic and aliphatic carbon of humic fractions and their respective complexes obtained through the analyses of bands $G$ and $\gamma$ are presented on Table 2.

Table 2. Ratio of the bands of aromatic carbons ( $\mathrm{G}$ band) and aliphatic carbons $(\gamma$ band) for samples of the humic fractions and their respective complexes

\begin{tabular}{lcc}
\hline Sample & $\begin{array}{c}\gamma \text { band } \\
\left(2 \theta=20.5^{\circ},\right. \\
\text { or } 0.43 \mathrm{~nm}), \text { aliphatic } \\
\text { carbons / } \%\end{array}$ & $\begin{array}{c}\text { G band } \\
\left(2 \theta=25.5^{\circ},\right. \\
\text { or } 0.35 \mathrm{~nm}), \text { aromatic } \\
\text { carbons / } \%\end{array}$ \\
\hline Fulvic acid (FA) & 52.70 & 47.30 \\
FA-Fe & 55.55 & 44.45 \\
FA-Zn & 34.97 & 65.03 \\
FA-Cu & 45.74 & 54.26 \\
Humic acid (HA) & 47.45 & 52.55 \\
HA-Fe & 63.59 & 36.41 \\
HA-Zn & 35.33 & 64.67 \\
HA-Cu & 43.11 & 56.89 \\
\hline
\end{tabular}

Both FA and HA presented similar ratios of aromatic carbon, with a difference of $5.25 \%$ higher for HA and it is possible that the FA structure is more compact and aromatic. However, the humification and aromaticity content are not only related to the qualitative composition of functional groups, but also to the structural reorganization of such compounds, for example, the modifications that occur when the humic fractions complex with metals. ${ }^{27,28}$ We highlight that for the FA-Zn and FA-Cu complexes the assigned peaks are not so intense, which may have impaired the calculation of aromatic and aliphatic carbon. 


\section{Thermogravimetric analysis}

The humic acid presented plots of mass loss in function of temperature in two main peaks: the first at a lower temperature (approximately $280{ }^{\circ} \mathrm{C}$ ) and the second at temperatures superior to $400{ }^{\circ} \mathrm{C}$. The main reactions characteristic of FA and HA are the dehydration until $200{ }^{\circ} \mathrm{C}$ followed by the elimination of functional groups

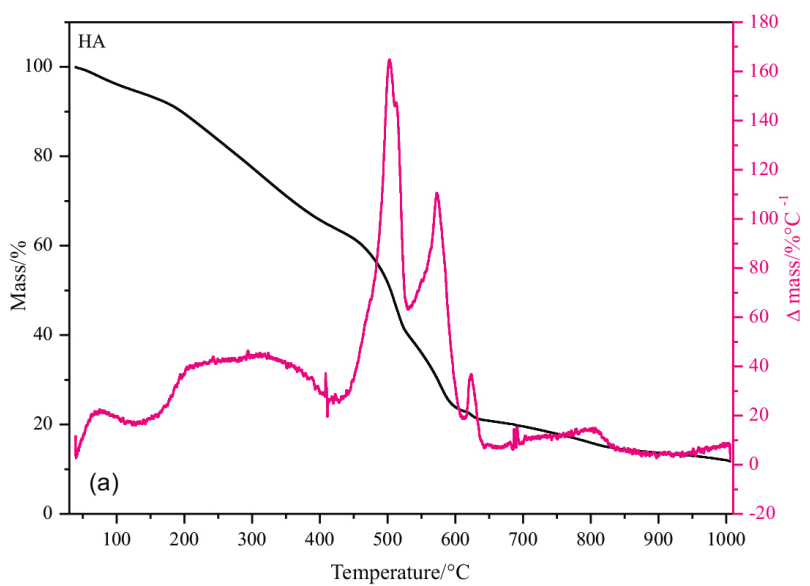

between 250 and $280{ }^{\circ} \mathrm{C}$, and finally the decomposition of nuclei above $400{ }^{\circ} \mathrm{C} .{ }^{13}$ The thermogravimetric curves are presented in the Figures 7 to 9 .

There was a continuous mass loss and FA presented more resistance to thermal decomposition than HA, which may be attributed to the higher number of aromatic groups. The complexes presented a lower resistance to thermal degradation with effective mass

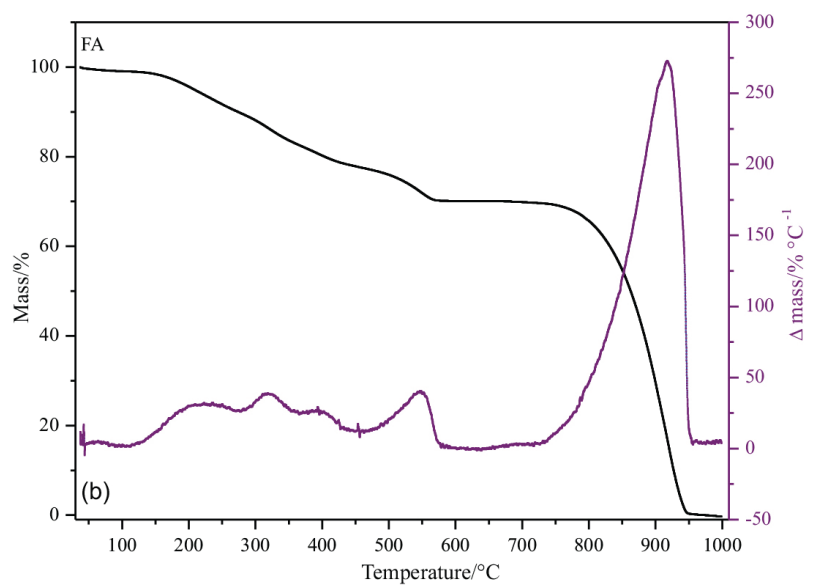

Figure 7. Thermogravimetry: TG and DTG curves of (a) humic acid (HA); (b) fulvic acid (FA).
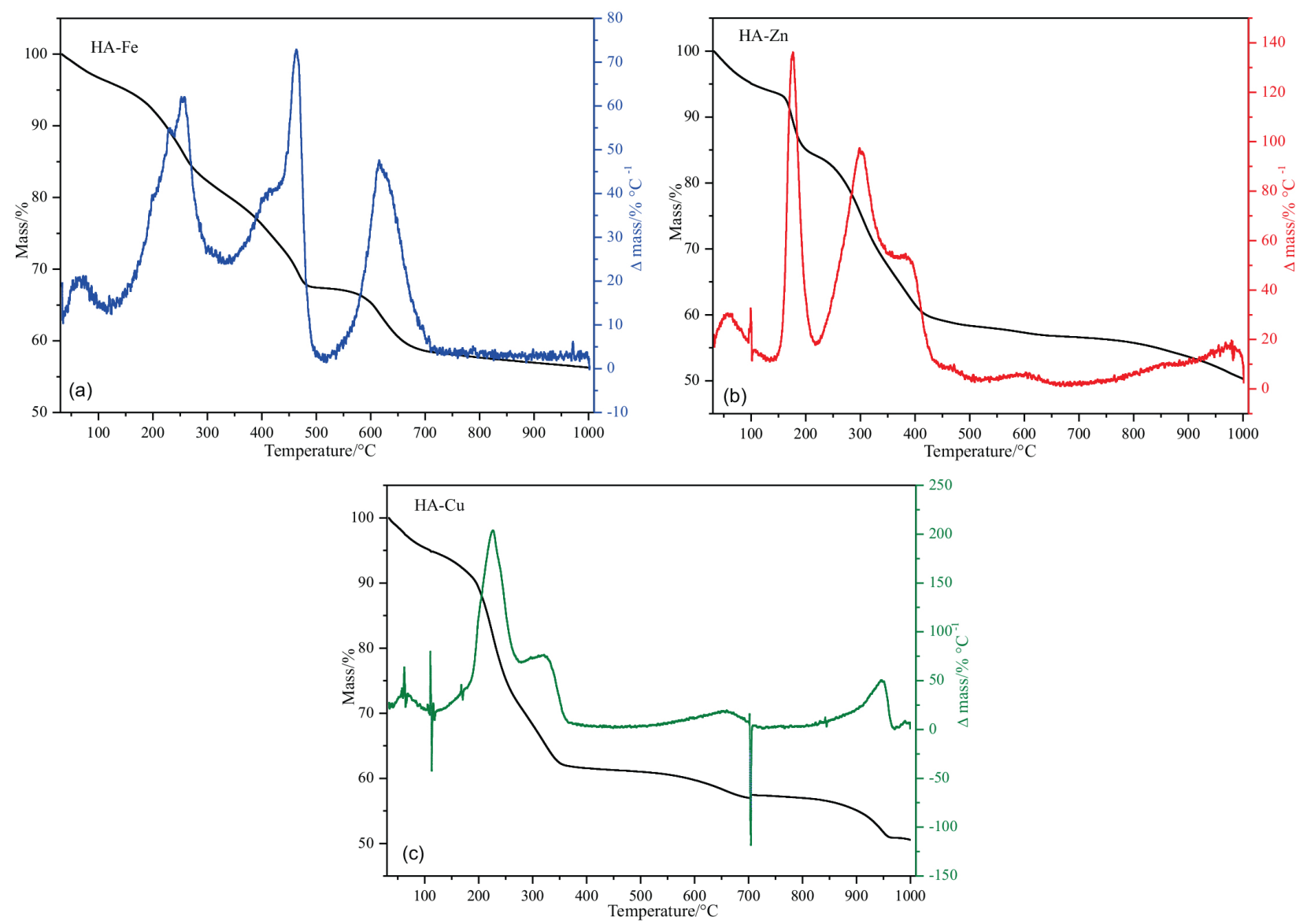

Figure 8. Thermogravimetry: TG and DTG curves of humic acid complex (a) with iron (HA-Fe); (b) with zinc (HA-Zn); (c) with copper (HA-Cu). 

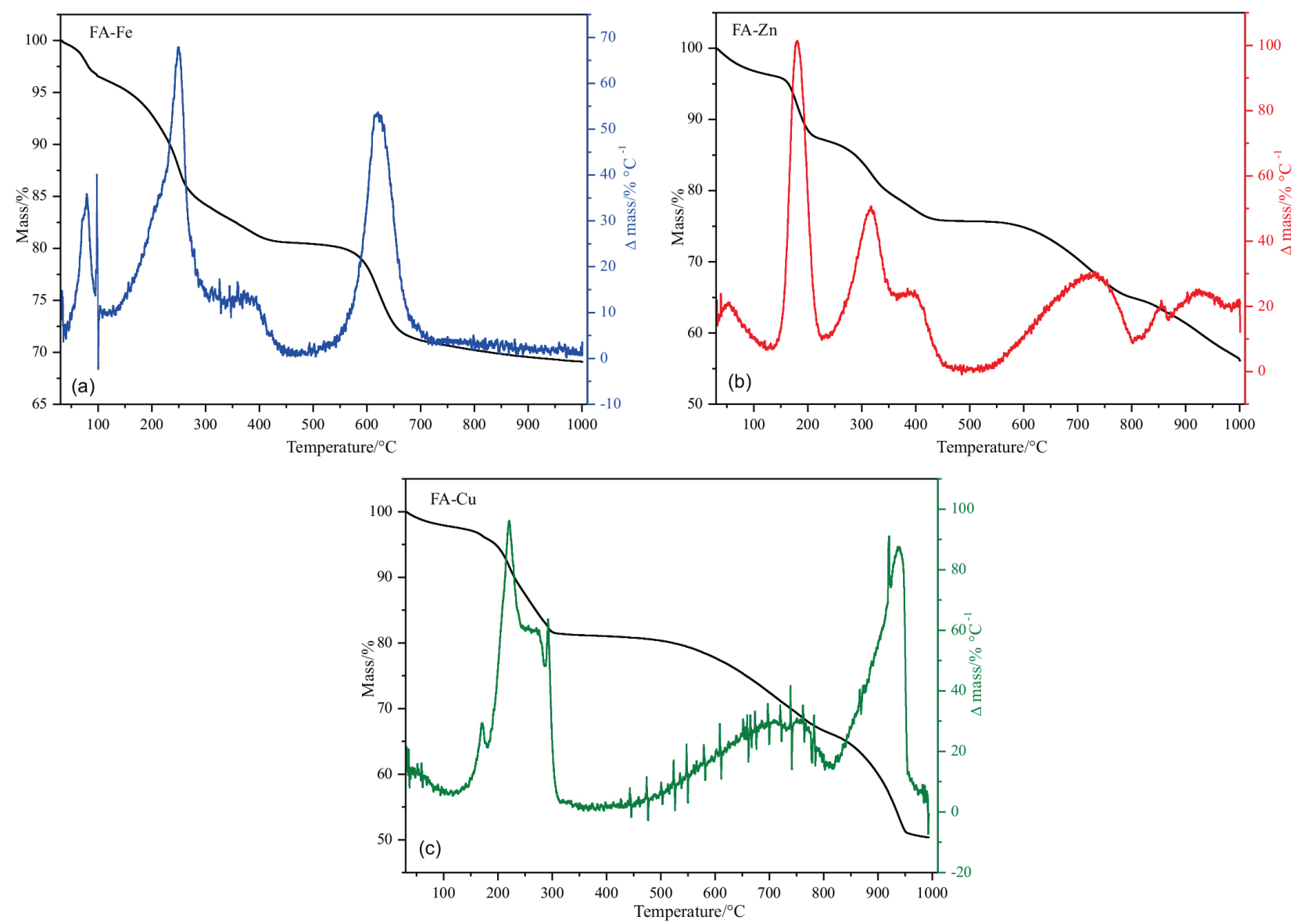

Figure 9. Thermogravimetry: TG and DTG curves of fulvic acid complex (a) with iron (FA-Fe); (b) with zinc (FA-Zn); (c) with copper (FA-Cu).

loss at a relatively lower temperature when compared to $\mathrm{HA}$ and FA.

Higher ash content is expected for complexes, since metals are thermally stable at high temperatures. The great mass loss of complexes at low temperatures occurs because the metal ion interrupts intermolecular forces that link individual parts of HSs, dissociating the structure and consequently destabilizing them. ${ }^{29}$ The mass loss at $300{ }^{\circ} \mathrm{C}$ probably corresponds to the decomposition of carboxylic, methyl, methylene and alcoholic groups and also the decomposition of carbohydrates present in the humic structure, while the mass loss above this temperature may be attributed to oxidation and polycondensation of aromatic structures. ${ }^{30}$

\section{Study of metal release}

The strong interaction of HSs with metal species allows the formation of complex HS-nutrients, thus influencing their availability and transport for the plants. The availability of nutrients (metals) is directly related to the desorption processes, which in general depends on the concentration of the added element, temperature, $\mathrm{pH}$ and amount of adsorbent/ complexant employed. Other determinant factor to favor the release process is the time of contact between the complex and the medium in which it is inserted. ${ }^{8,31}$

The curves that represent the release of iron, copper and zinc complexed with HA and FA are presented on Figure 10.

The complexes HA-Fe and HA-Zn presented similar release tendencies, however, a distinct behavior was observed regarding the FA complexes. Since HSs have complex structures, the release of metals does not occur linearly due to the restructuring of the molecular conformation of such substances. The metals reorganize within the HSs and, therefore, the metal will be released only if there is exchange with elements with higher affinity than the complexed metal, a process known as cation-exchange capacity. ${ }^{32}$

The concentration of metals released by the complexes HA-metal and FA-metal (Cu, $\mathrm{Zn}$ and $\mathrm{Fe}) 0.2 \mathrm{~mol} \mathrm{~L}^{-1}$ in relation to the time are presented on Table 3 .

In relation to the curves of release and concentrations, the complexes that first attained the equilibrium time and then released faster were $\mathrm{HA}-\mathrm{Cu}$ and FA-Cu. According to the Association of American Plant Food Control Officials (AAPFCO), ${ }^{33}$ fertilizers that delay the adsorption time, 

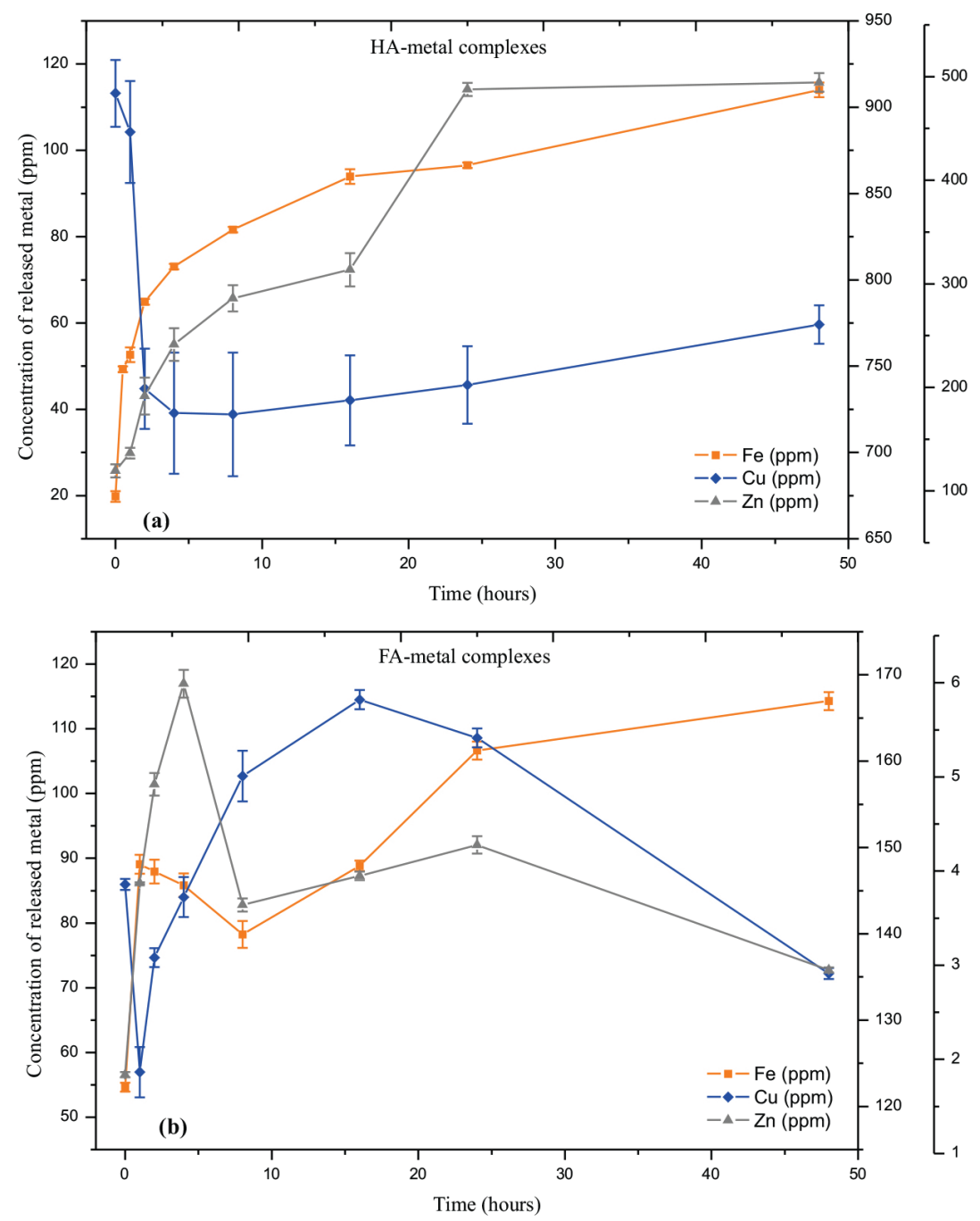

Figure 10. Curves of the release of the humic acid (a) and fulvic acid (b) complexed with the metals: iron, copper and zinc.

Table 3. Concentration of metal released in solution with respect to time. Complexes of humic and fulvic acid with metals: copper, iron and zinc

\begin{tabular}{|c|c|c|c|c|c|c|}
\hline \multirow{2}{*}{ time / h } & \multicolumn{6}{|c|}{ Concentration of metal released in solution of the complexes / ppm } \\
\hline & $\mathrm{HA}-\mathrm{Cu}$ & HA-Zn & $\mathrm{HA}-\mathrm{Fe}$ & $\mathrm{FA}-\mathrm{Cu}$ & FA-Zn & FA-Fe \\
\hline 0 & 908.04 & 119.41 & 19.81 & 145.73 & 1.84 & 54.64 \\
\hline 1 & 885.72 & 136.52 & 52.63 & 123.96 & 3.87 & 89.08 \\
\hline 2 & 736.92 & 191.58 & 64.91 & 137.24 & 4.92 & 87.92 \\
\hline 4 & 722.79 & 241.42 & 73.10 & 144.25 & 5.99 & 85.84 \\
\hline 8 & 722.05 & 286.06 & 81.65 & 158.27 & 3.64 & 78.22 \\
\hline 16 & 730.23 & 313.59 & 96.53 & 167.12 & 3.95 & 88.85 \\
\hline 24 & 739.16 & 487.69 & 92.07 & 162.69 & 4.27 & 106.64 \\
\hline 48 & 774.12 & 494.38 & 114.02 & 135.39 & 2.95 & 114.27 \\
\hline Total & 6219.03 & 2270.65 & 594.72 & 1173.72 & 31.43 & 705.46 \\
\hline
\end{tabular}

increasing the availability of nutrients for the plants when compared to a conventional, are considered of slow or controlled release. According to the requirements proposed by AAPFCO, the complex HA-Fe may be considered of slow release.
Mathematical modeling applied to the release essays

The semi-empirical model of Korsmeyer Peppas was applied to the humic fractions with metals in order to elucidate the type of mechanism that guides the release system. 
$\mathrm{M}_{\mathrm{t}} / \mathrm{M}_{\infty}=\mathrm{Kt}^{\mathrm{n}}$

where $\mathrm{K}$ is the release constant that incorporates structural and geometric characteristics of the mechanism; $n$ is the release exponent that, according to the numeric value assumed, characterizes the mechanism of nutrients release; $M_{t}$ is the metal release at time $t ; M_{\infty}$ is the quantity of metal release at infinite time; and $\mathrm{t}$ is agitation time.

In general, this equation 3 is used to interpret and describe the release of compounds when the prevailing mechanism is not completely elucidated or results from the combination of two apparently independent processes: one due to the nutrient transport that follows the Fick laws, or Fickian transport, and other non-Fickian consequence of swelling/relaxation phenomena of the polymeric matrix (dynamics expansion), which involve the transition of a semi-rigid state to other more flexible called Case-II transport. ${ }^{34-37}$ The analysis of model was conducted in function of values obtained from the nonlinear regressions of treatments, in which it is possible to determine the constant of the release $(\mathrm{K})$ and the value of release exponent (n). Table 4 presents the data extracted from equation 3.

Table 4. Values of release constants (K). Exponent of release (n) and correlation coefficient $\left(\mathrm{R}^{2}\right)$ obtained from the curves of release of the organomineral complexes

\begin{tabular}{lccc}
\hline Sample & $\begin{array}{c}\text { Release } \\
\text { constant }(\mathrm{K})\end{array}$ & $\begin{array}{c}\text { Release } \\
\text { exponent }(\mathrm{n})\end{array}$ & $\begin{array}{c}\text { Correlation } \\
\text { coefficient }\left(\mathrm{R}^{2}\right)\end{array}$ \\
\hline HA-Fe & $7.46 \times 10^{-2}$ & 0.18 & 0.98 \\
HA-Zn & $1.22 \times 10^{-1}$ & 0.32 & 0.94 \\
HA-Cu & $2.82 \times 10^{-1}$ & -0.03 & 0.96 \\
FA-Fe & $8.96 \times 10^{-2}$ & 0.07 & 0.92 \\
FA-Zn & $2.20 \times 10^{-2}$ & -0.07 & 0.70 \\
FA-Cu & $1.16 \times 10^{-1}$ & 0.04 & 0.92 \\
\hline
\end{tabular}

The values of release exponent presented on Table 4 were lower than 0.43 , thus indicating that the release mechanism controlling the system occurs by Fickian diffusion. ${ }^{35}$ According to the values of $\mathrm{K}$, it is possible to conclude that the higher this value is, the faster the metal will be released in the buffering medium. Based on equations, this fact is applied to all the analyzed complexes, that obeyed a state of dynamic equilibrium and present a good coefficient of correlation, with the exception of the FA-Zn complex.

The release behavior of the copper complex may be classified as burst effect, which occurs when an initial amount of metal results in the release of metal in the surface of the matrix system or also by alterations verified in the system with consequent immediate release followed by the slower release. ${ }^{38}$ The ion $\mathrm{Cu}\left(\mathrm{H}_{2} \mathrm{O}\right)_{6}{ }^{2+}$ presents a relatively fast exchange rate for a small divalent cation, which may be attributed to the distortion of its geometry. Hexa-coordinated complexes of $\mathrm{Cu}^{2+}$ with octahedron geometry present tetragonal distortions known as Jahn-Teller effect and, therefore, waters of coordination in the axial positions may be more easily released. This fact may explain the high degree of instability of $\mathrm{Cu}^{2+}$ complexes with humic fractions.

There are two types of coordination places in the hexa-coordinates tetragonally distorted complexes: the axial and equatorial. The waters of coordination in the axial position are weakly linked to the $\mathrm{Cu}^{2+}$ cation through a very long bond and, therefore, are more easily substituted. Waters located in equatorial positions are strongly linked and the exchange occurs more slowly with other binders. ${ }^{39}$

\section{Conclusions}

The fulvic acids presented lower atomic ratios $\mathrm{H} / \mathrm{C}$ and $\mathrm{N} / \mathrm{C}$ and higher ratio $\mathrm{O} / \mathrm{C}$, confirming the presence of a chemical structure with greater aromatic character. The stretch displacement in the range of $1700 \mathrm{~cm}^{-1}$ for 1650 to $1550 \mathrm{~cm}^{-1}$ suggests the complexation of metals with carboxylates. The FA complexes obtained higher percentages for the band $\mathrm{G}$, higher resistance to thermal degradation and lower percentage of metal release, which represent more aromatic structures. The interaction of HSs with metals provides the formation of complexes with different characteristics and stability with capacity to control the availability of nutrients in the environment.

\section{Supplementary Information}

Supplementary information (calibration curves for the complexes HA-metals and FA-metals; limits of detection (LOD) and quantification (LOQ) from the calibration curves) is available free of charge at http://jbcs.sbq.org.br as PDF file.

\section{Acknowledgments}

The authors thank to Coordenação de Aperfeiçoamento de Pessoal de Nível Superior (CAPES) by the scholarship; Instituto de Química of Universidade Federal de Alfenas (UNIFAL); Laboratório de Análise e Caracterização de Fármacos (LACFar-UNIFAL); and Fundação de Amparo à Pesquisa do Estado de Minas Gerais (FAPEMIG).

\section{References}

1. Baldotto, M. A.; Baldotto, L. E. B.; Rev. Ceres 2014, 61, 856. 
2. Brondi, A. M.; Daniel, J. S. P.; Castro, V. X. M.; Bertoli, A. C.; Garcia, J. S.; Trevisan, M. G.; Commun. Soil Sci. Plant Anal. 2016, 47, 2506.

3. Witter, E.; Kirchmann, H.; Plant Soil 1989, 115, 53.

4. Piccolo, A. In Humic Substances in Terrestrial Ecosystems; Piccolo, A., ed.; Elsevier Science B. V.: Amsterdam, Netherlands, 1996, ch. 5.

5. Kulikova, N. A.; Perminova, I. V.; Environ. Sci. Technol. 2002, 36, 3720 .

6. Segnini, A.; Posadas, A.; Quiroz, R.; Milori, D. M. B. P.; Saab, S. C.; Neto, L. M.; Vaz, C. M. P.; Soil Sci. Soc. Am. J. 2010, 74, 2246.

7. Segnini, A.; Souza, D.; Alves, A.; Novotny, E. H.; Milori, D. M. B. P.; Silva, D.; Lopes, W. T.; Bonagamba, T. J.; Posadas, A.; Quiroz, R.; Soil Sci. Soc. Am. J. 2013, 77, 673.

8. García-Mina, J. M.; Antolín, M. C.; Sanchez-Diaz, M.; Plant Soil 2004, 258, 57.

9. Shaviv, A.; Advances in Agronomy, vol. 71; Sparks, D. L., ed.; Academic Press: Cambridge, USA, 2001, p. 1.

10. http://humic-substances.org/isolation-of-ihss-soil-fulvic-andhumic-acids/, accessed in June 2017.

11. Litvin, V. A.; Minaev, B. F.; Mater. Chem. Phys. 2014, 144, 168.

12. Litvin, V. A.; Galagan, R. L.; Minaev, B. F.; Colloids Surf. Physicochem. Eng. Asp. 2012, 414, 234.

13. Stevenson, F. J.; Humus Chemistry: Genesis, Composition, Reactions; John Wiley \& Sons: New Jersey, USA, 1994.

14. Canellas, L. P.; Humosfera: Tratado Preliminar sobre a Química das Substâncias Húmicas; Ed do Autor: Campos dos Goytacazes, Brazil, 2005.

15. Silverstein, R. M.; Webster, F. X.; Kiemle, D. J.; Spectrometric Identification of Organic Compounds; Livros Técnicos e Científicos: Rio de Janeiro, Brazil, 2006.

16. Moreira, M. A.; Cormanich, R. A.; de Rezende, F. M. P.; Silla, J. M.; Tormena, C. F.; Rittner, R.; Ramalho, T. C.; Freitas, M. P.; J. Mol. Struct. 2012, 1009, 11.

17. Balachandran, V.; Lalitha, S.; Rajeswari, S.; Rastogi, V. K.; Spectrochim. Acta, Part A 2014, 121, 575.

18. Silverstein, R. M.; Identificação Espectrométrica de Compostos Orgânicos; Livros Técnicos e Científicos: Rio de Janeiro, Brazil, 2000.

19. Bertoli, A. C.; Garcia, J. S.; Trevisan, M. G.; Ramalho, T. C.; Freitas, M. P.; BioMetals 2016, 29, 275.
20. Chen, Z.; Pawluk, S.; Geoderma 1995, 65, 173.

21. Schnitzer, M. In Developments in Soil Science, vol. 8; Schnitzer, M.; Khan, S. U., eds.; Elsevier Science: Amsterdam, Netherlands, 1978, ch. 1.

22. Schnitzer, M.; Kodama, H.; Ripmeester, J. A.; Soil Sci. Soc. Am. J. 1991, 55, 745.

23. Xing, B.; Chen, Z.; Soil Sci. 1999, 164, 40.

24. Rupiasih, N. N.; Vidyasagar, P. B.; Int. J. Des. Nat. Ecodyn. 2009, 4, 32.

25. Wu, J.; Wu, M.; Li, C.; Yu, G.; PLoS One 2014, 9, 8.

26. Tomazoni, J. C.; Guimarães, E.; Rev. Bras. Geogr. Física 2015 , 8,721 .

27. Brighenti, C. R. G.; Reis, E. L.; Reis, C.; Ecletica Quim. 2010, 35,69 .

28. Wang, N.; Li, B.; Qiao, F.; Sun, J.; Fan, H.; Ai, S.; J. Mater. Chem. B 2015, 3, 7718.

29. Klučáková, M.; Nováčková, K.; J. Soils Sediments 2014, 14, 360.

30. Pietro, M.; Paola, C.; Thermochim. Acta 2004, 413, 209.

31. Evangelou, V. P.; Environmental Soil and Water Chemistry: Principles and Applications; John Wiley \& Sons: New Jersey, USA, 1998.

32. Sempeho, S. I.; Kim, H. T.; Mubofu, E.; Hilonga, A.; Adv. Chem. 2014, $1,16$.

33. Trenkel, M. E.; Slow- and Controlled-Release and Stabilized Fertilizers: An Option for Enhancing Nutrient Use Efficiency in Agriculture; IFA: Paris, France, 2010.

34. Grillo, R.; Pereira, A. E. S.; Nishisaka, C. S.; de Lima, R.; Oehlke, K.; Greiner, R.; Fraceto, L. F.; J. Hazard. Mater. 2014, 278, 163.

35. Korsmeyer, R. W.; Gurny, R.; Doelker, E.; Buri, P.; Peppas, N. A.; Int. J. Pharm. 1983, 15, 25.

36. Lopes, C. M.; Lobo, J. M. S.; Costa, P.; Rev. Bras. Cienc. Farm. 2005, 41, 143.

37. Siepmann, J.; Peppas, N. A.; Adv. Drug Delivery Rev. 2001, 48, 139.

38. Fu, Y.; Kao, W. J.; Expert Opin. Drug Delivery 2010, 7, 429.

39. McBride, M. B.; Environmental Chemistry of Soils; Oxford University Press: Oxford, England, 1994.

Submitted: March 22, 2017

Published online: June 28, 2017 